\title{
An assessment of the chemistry laboratory learning environments and teacher student interactions at the higher secondary level
}

Gupta, Adit

MIER College of Education, India (adit@mier.in)

Sharma, Anita

MIER College of Education, India (anitasharma89786@gmail.com)

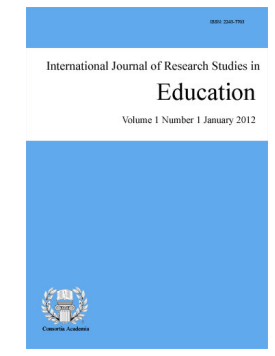

ISSN: $2243-7703$ Online ISSN: 2243-7711

OPEN ACCESS

\section{Abstract}

Chemistry laboratories provide students with a chance to test their ideas and learn difficult concepts by performing experiments. The study assesses students' perceptions of their learning environments and their teacher-student interactions in a chemistry laboratory setting at the higher secondary level in selected private schools using the Science Laboratory Environment Inventory (SLEI) and Questionnaire on Teacher Interaction (QTI). The sample consists of 250 students studying in classes 11th and 12th. The learning environments in the chemistry laboratory at the higher secondary level show that the mean scores of the preferred form of the SLEI are higher than the actual form. This means that the students' preferred learning environments that are more open ended in terms of decision making on the part of the students, seek better material support to perform the laboratory experiments in terms of equipment, chemicals and more cohesiveness with one another in terms of providing support for each other etc. The results on the QTI show that the students see their teachers as good leaders most of the time and have also rated their teachers in terms of exhibiting helpful and friendly nature, understanding and giving students freedom and responsibility in the chemistry laboratory. No significant gender differences have been reported in the chemistry laboratory learning environments however, significant gender differences were found to exist in students' perceptions of their teacher interpersonal behavior in chemistry laboratory settings.

Keywords: chemistry laboratory; learning environments; teacher-student interactions; secondary level, Science Laboratory Environment Inventory (SLEI) 


\section{An assessment of the chemistry laboratory learning environments and teacher student interactions at the higher secondary level}

\section{Introduction}

The chemistry laboratory is designed to support and illustrate chemical concepts studied in the lecture portion of the course, as well as to introduce important laboratory techniques and encourage analytical thinking. Of course, teachers cannot perfectly synchronize the coverage of material in the lecture and the laboratory, but teachers will attempt to make connections whenever possible. Along with concepts and chemistry covered in lecture, the laboratory portion of the course will present some additional chemistry, both theoretical and practical.

Chemistry practical work can be used to help students achieve a number of learning outcomes, including: getting a feel for natural phenomenon, developing investigation skills and processes, providing a platform of experiences on which conceptual understanding can be built, giving students a sense of nature of science, and the excitement of inquiry and discovery. Practical work provides opportunities for students to develop learning outcomes that contribute to scientific literacy including the skills and understanding needed to conduct scientific investigations and to critically evaluate the claims made by others based on scientific evidence (Venville \& Dawson, 2004).

Chemistry Laboratory activities have had a distinctive and central role in the science curriculum and science educators have suggested that many benefits accrue from engaging students in chemistry laboratory activities (Hofstein \& Lunetta, 1982; Lunetta, 1998). More specifically, when properly developed, inquiry-centered laboratories have the potential to enhance students' constructive learning, conceptual understanding and understanding of the nature of science. Inquiry-type experiences are especially effective if conducted in the context of, and integrated with, the conceptual development of the topic taught. The National Science Education Standards (National Research Council 1996) presented a statement on teaching science as inquiry. The Standards define what all students should know and what kind of learning experiences they need to achieve scientific literacy. Moreover, they reaffirm the conviction that inquiry is central to the achievement of scientific literacy. The Standards use the term inquiry in two ways: (1) inquires content understanding (in which students have opportunities to construct concepts, patterns and meaning about an idea to explain what they experience) and (2) inquiry as abilities (Bybee, 2000). Under the heading of abilities or skills, Bybee includes identifying questions, designing and conducting scientific investigations, formulating and revising scientific explanations, recognizing and analyzing alternative explanations, and communicating and defending scientific arguments. It is suggested that many of these abilities are in alignment with those that characterize inquiry-type laboratories.

Hofstein and Walberg (1995) reported that inquiry-type laboratories are central to learning science, because students are involved in the process of conceiving problems, formulating hypotheses, designing experiments, gathering and analyzing data, and drawing conclusions about scientific problems or science phenomena. These, it is suggested, should be integrated with the other complementary activities such as the development of scientific concepts and related scientific skills and experiences. One must remember that student inquiry can range from independently conducted research on different issues to the investigation of a research question by the entire class (Lunetta, 1998). In conclusion, there is no doubt that inquiry teaching and learning poses a challenge to both teachers and students (Kracjik, Mamlok, \& Hug, 2000).

The study of classroom and school learning environments and their effects on students' learning has been going on for more than a century. Past efforts in the study of the learning environments and its determinants have indicated that it plays a major role in improving teaching and learning in primary, secondary and higher education. The laboratory experiment is an important part of science teaching. Many studies show that 
Assessment of the chemistry learning environments and teacher student interactions at secondary level

experiments in laboratory influence students to have better attitudes toward chemistry laboratories and learning outcomes (Yager, 1991; Stohr-Hunt, 1996; Thompson \& Soyibo, 2002 as cited in Parkinson, 2004). Furthermore, laboratory experiments can help students to understand abstract concepts in chemistry. Practical work in chemistry laboratories is also fun and interesting for the students. As a result, they are motivated to explore the material which is related to the topics in the classroom (Borrows, 1999 as cited in Parkinson, 2004). According to Swain et al. (2000) as cited in Parkinson (2004), there are four aims of practical work in the chemistry laboratory which is encouraging students to (1) laboratory practice seeing problems and solve it, (2) find the facts and new principles, (3) develop ability to co-operate, (4) develop critical attitude. However, teachers' role to help the students to achieve these positive aims of practical work is very important. One of teachers' roles is to create a positive learning environment in the chemistry laboratory in order to achieve the best educational performance.

\subsection{Objectives of the study}

The main objectives of this study are: a) to assess the learning environments in a chemistry laboratory at the higher secondary level; b) to assess the teacher-student interactions in a chemistry laboratory learning environment; c) to investigate whether significant gender differences exist in students perceptions of their chemistry laboratory learning environments and d) to investigate whether significant gender differences exist in students perceptions of their teacher interpersonal behavior in a chemistry laboratory settings.

\section{Review of literature}

The review of literature provides information regarding the contribution of science laboratories in improving the process of teaching chemistry in different countries in general and India in particular. Since the main aim of this study is to assess the learning environments of the chemistry laboratories, hence the review highlights the use of a widely applicable tool i.e. Science Laboratory Environment Inventory (SLEI) for assessing such environments. The review also deals with the aspect of teacher-student interactions as measured by the Questionnaire on Teacher Interaction (QTI).

\subsection{Research Studies using Science Laboratory Environment Inventory (SLEI)}

In Korea, Fraser and Lee (2009) successfully used and cross-validated the SLEI. The questionnaire was first translated into Korean language and then used with 439 high school science students divided among three streams (science-independent, science-oriented and humanities). Once again, the SLEI proved to be valid and useful for use within the context of the study. While, Ahmad, Osman, and Halim (2013) conducted a survey to determine teacher's perception of the science laboratory learning environments and the relationship between different aspects of this environment and satisfaction from teaching and learning. Teacher' perceptions of psychosocial aspects were measured by use of the Science Laboratory Environment Inventory (SLEI), whereas perceptions of physical aspects were measured by use of the Physical Science Laboratory Environment Inventory. The level of satisfaction was measured by use of a satisfaction scale (sc). Data were collected from 800 science teachers in secondary schools in Malaysia. Analysis of findings revealed that teachers have positive attitudes on all SLEI scales, with the exception of the open-ended scale. In terms of physical aspects, teachers regard lighting and technology as highly important but furniture and equipment, space, air quality and safety as of moderate importance only. Results also showed that teacher's satisfaction from teaching in the laboratory was positive. Subsequent analysis revealed a significant predictive relationship between teachers' perception of science laboratory learning environments and their teaching and learning satisfaction.

In a study conducted by Gupta, Koul, and Sharma (2015) the student's perceptions of the Science laboratory learning environments at the Senior Secondary were studied. This study was the first of its kind in India and reports the use of the modified form of the SLEI for assessing the students' perceptions of their learning environments in general science laboratories. Analysis of data of 460 students from higher secondary i.e. grade 
Gupta, A., \& Sharma, A.

10th to 12 th provides evidence for the reliability and validity of the questionnaires. The same data was taken for studying the gender differences and the associations between students' perceptions of their science laboratory learning environments with their attitude towards science. The results suggested that positive associations existed between students' perceptions of their laboratory learning environments and their attitude towards science. Gender differences in favor of female students were also reported on two scales of the SLEI and Attitude towards Science Scale.

\subsection{Research Studies using Questionnaire on Teacher Interaction (QTI)}

Gupta and Fisher (2011) conducted a study on teacher-student interactions in a technology-supported science classroom environment in relation to selected learner outcomes: an Indian study. This study reports the use of Questionnaire on Teacher Interaction (QTI) for assessing the students' perceptions of their teachers' interpersonal behavior in a technology-supported science classroom environment in an Indian school. Analysis of data of 705 students from 15 classes provides evidence for reliability and validity of the Questionnaire in Indian settings to be used at the secondary level. The same data was also used for studying gender differences and the associations between students' perceptions of their teachers' interpersonal behavior with three learner outcomes i.e. their attitude towards science, academic efficacy and academic achievement which had been reported as significant.

In a study conducted by Sharma (2014) the teacher controls the teaching process and directs the activities of students on a day to day basis. The interactions that teachers have with their students determine the nature of their interpersonal relationships and enable the teacher to improve their teaching practices. The purpose of this study was to assess the teacher educators' interpersonal education classroom. A sample of 250 students including both male and female teacher trainees was collected from five colleges of education in Jammu city. Statistical analyses including internal consistency reliability, scale validity ANOVA etc. was used. The descriptive statistics like mean, standard deviation, correlation, regression and t-test was used. Data analysis reveals that usually the teacher trainees see their teacher educators as good leaders. Results on investigation of gender differences suggest that out of eight scales of the QTI only one scale i.e. Student Responsibility/Freedom is statistically significant.

In a study conducted by Kumara (2015) the integration of Kinect based applications into the Taiwan classrooms make students' learning experience very active and joyful. This study proposes a system for assessment in a smart classroom environment. An interactive framework is designed using Microsoft Kinect sensor for virtual learning environment with new gesture-based questions supporting QTI-based assessment, and further a rich set of gesture commands are also introduced for practical usage in the classroom. Proposed system was experimented with teachers and students then collected feedback of the users using a usability questionnaire. The results show that the participants are satisfied with the system and it demonstrates that the proposed system is simple to use, provides better functionality and motivates student learning by assessment.

\subsection{Sample for the study}

A quantitative research methodology was adopted for this study. Purposive sampling technique was used to collect the sample for the study. The sample involved chemistry classes at the higher secondary stage in selected schools of Jammu. The sample was chosen carefully so as to be representative of the population and comprises of coeducational classes in order to permit an unbiased test of gender differences. The sample included $25011^{\text {th }}$ and $12^{\text {th }}$ class students from five schools of Jammu. Out of 250 students 151 were male students and 99 female students.

\subsection{Research Instrument Selection}

The field of learning environments has expanded at a phenomenal pace in the last three decades and a wide variety of instruments have been developed for assessing the psychosocial learning environments in a classroom 
situation. While selecting the instruments for this study a number of factors were considered. Firstly, it was made sure that the instrument was statistically reliable, valid and widely applicable, and secondly, caution was taken with regard to the language and wording as most of the instruments had been developed in western countries and had to be used in Indian school settings.

After reviewing a number of instruments, the Science Laboratory Environment Inventory (SLEI) (Fraser, Giddings \& McRobbie, 1995; Fraser \& McRobbie, 1995) and the Questionnaire on Teacher Interaction (QTI) (Wubbels \& Levy, 1993) were selected to assess the learning environments in a chemistry laboratory and teacher interpersonal behavior. Both these instruments have been widely used in a number of research studies as given in the review of literature section.

Science Laboratory Environment Inventory (SLEI) Questionnaire - Science Laboratory Environment Inventory (SLEI) was developed by Fraser, Giddings \& McRobbie 1995; Fraser \& McRobbie 1995; Fraser, McRobbie \& Giddings 1993). The SLEI has five scales (each with seven items) which are Student Cohesiveness (SC), Open-Endness (OE), Integration (I), Rule Clarity (RC), and Material Environment (ME) and five response alternatives are Almost Never, Seldom, Sometimes, Often and Very Often. The SLEI was field tested and validated simultaneously with a sample of over 5,447 students in 269 classes in six different countries (the USA, Canada, England, Israel, Australia and Nigeria). The SLEI questionnaire is available in two forms, the Actual and the Preferred. The actual form measures the classroom environment in its current form while the preferred form measures perceptions of students' ideal of preferred classroom environments. A description of the Science Laboratory Environment Inventory (SLEI) is given in Table 1.

\section{Table 1}

Description of Science Laboratory Environment Inventory (SLEI) Scale

\begin{tabular}{lll}
\hline \multicolumn{1}{c}{ Scale Name } & \multicolumn{1}{c}{ Scale Description } & \multicolumn{1}{c}{ Sample Item } \\
\hline Student Cohesiveness & $\begin{array}{l}\text { The extent to which student know, help } \\
\text { and are supportive of one another. }\end{array}$ & $\begin{array}{l}\text { I am friendly with students in } \\
\text { this laboratory class }\end{array}$ \\
Open Endedness & $\begin{array}{l}\text { The extent to which the laboratory } \\
\text { activities emphasize an open-ended } \\
\text { divergent approach to experimentation. }\end{array}$ & $\begin{array}{l}\text { I can pursue my own science } \\
\text { interests in this laboratory class }\end{array}$
\end{tabular}

Integration

Rule Clarity

Material Environment
The extent to which the laboratory activities are integrated with non-laboratory and theory classes.

The extent to which the behavior in the laboratory is guided by formal rules.

The extent to which the laboratory equipment and materials are adequate.
My regular science class work is integrated with laboratory activities.

I am required to follow certain rules in the laboratory.

The laboratory equipment, which I use, is in proper working order.

Note. Responses of the items are scored 1, 2, 3, 4, and 5 respectively, from Almost Never, Seldom, Sometimes, Often to Almost Always. Missing or invalid responses are scored 3, the mid-range value.

Questionnaire on Teacher Interaction (QTI) - The Questionnaire on Teacher Interaction (QTI : Wubbles \& Levy, 1991, 1993) was designed to assess teacher-student interpersonal behavior in lower secondary classroom and developed out of a need to measure secondary students' and teachers' perceptions of teacher behavior. In the early 1980s, the original version of the QTI in Dutch language was developed in four trials in the Netherlands and had 77 items, which were arranged in the eight scales. The eight scales are Leadership, Helping/Friendly, Understanding, Student Responsibility/Freedom, Uncertain, Dissatisfied, Admonishing and Strict. A description of the Questionnaire on Teacher Interaction is given in Table 2. 
Gupta, A., \& Sharma, A.

Table 2

Description of Questionnaire on Teacher Interaction (QTI)

\begin{tabular}{|c|c|c|}
\hline Scale Name & Scale Description & $\begin{array}{l}\text { Sample Item } \\
\end{array}$ \\
\hline Leadership & $\begin{array}{l}\text { Extent to which teacher provides } \\
\text { leadership to class and holds student } \\
\text { attention. }\end{array}$ & $\begin{array}{l}\text { The teacher talks enthusiastically about his/her } \\
\text { subject. }\end{array}$ \\
\hline Helping/Friendly & $\begin{array}{l}\text { Extent to which the teacher is } \\
\text { friendly and helpful towards } \\
\text { students. }\end{array}$ & This teacher helps us with our work. \\
\hline Understanding & $\begin{array}{l}\text { Extent to which teacher shows } \\
\text { understanding and care to students. }\end{array}$ & This teacher is willing to explain things again. \\
\hline $\begin{array}{l}\text { Student Responsibility/ } \\
\text { Freedom }\end{array}$ & $\begin{array}{l}\text { Extent to which the students are } \\
\text { given opportunities to assume } \\
\text { responsibilities for their own } \\
\text { activities. }\end{array}$ & This teacher is lenient. \\
\hline Uncertain & $\begin{array}{l}\text { Extent to which teacher exhibits } \\
\text { his/her uncertainty. }\end{array}$ & This teacher is hesitant. \\
\hline Dissatisfied & $\begin{array}{l}\text { Extent to which teacher shows } \\
\text { unhappiness/dissatisfaction with the } \\
\text { students. }\end{array}$ & This teacher thinks that we cheat. \\
\hline Admonishing & $\begin{array}{l}\text { Extent to which the teacher shows } \\
\text { anger/temper and is impatient in } \\
\text { class. }\end{array}$ & This teacher thinks we that cheat. \\
\hline Strict & $\begin{array}{l}\text { Extent to which the teacher is strict } \\
\text { with demands of the students. }\end{array}$ & This teacher's tests are hard. \\
\hline \multicolumn{3}{|c|}{$\begin{array}{l}\text { Note. Responses of the items are scored } 1,2,3,4 \text {, and } 5 \text { respectively, from Almost Never, Seldom, Sometimes, Often to Almost Always. } \\
\text { Missing or invalid responses are scored } 3 \text {, the mid-range value. }\end{array}$} \\
\hline \multicolumn{3}{|c|}{2.5 Reliability and validity of tools } \\
\hline \multicolumn{3}{|c|}{$\begin{array}{l}\text { Validation of SLEI - A sample of } 250 \text { students was used to collect the data for the SLEI. Two indices for } \\
\text { scale reliability and validity were generated for both the Actual and Preferred Forms separately. The Cronbach } \\
\text { alpha reliability coefficient was used as an index of scale internal consistency indicating the consistency of the } \\
\text { test items relative to other test items, which are designed to measure the same construct of interest. A } \\
\text { discriminant validity index (namely, the mean correlation of a scale with other scales) was used as evidence that } \\
\text { each SLEI scale measures a separate dimension that is distinct from the other scales in this questionnaire. Table } 3 \\
\text { illustrates the results for the Internal Consistency Reliability and the Discriminant Validity (Mean Correlation } \\
\text { with other Scales) for the five scales of Science Laboratory Environment Inventory (SLEI). }\end{array}$} \\
\hline
\end{tabular}

Table 3

Internal Consistency Reliability, Discriminant Validity of the Actual and Preferred forms of the SLEI

\begin{tabular}{|c|c|c|c|c|c|}
\hline \multirow{3}{*}{ Scale Name } & \multirow{3}{*}{$\begin{array}{c}\text { No. } \\
\text { of } \\
\text { items }\end{array}$} & \multicolumn{2}{|c|}{ Alpha } & \multirow{2}{*}{\multicolumn{2}{|c|}{$\begin{array}{c}\text { Mean Correlation } \\
\text { with other scales }\end{array}$}} \\
\hline & & Items & Reliability & & \\
\hline & & Act. & Pref. & Act. & Pref. \\
\hline Student Cohesiveness (SC) & 7 & 0.63 & 0.71 & 0.73 & 0.78 \\
\hline Open Endednes (OE) & 7 & 0.63 & 0.74 & 0.75 & 0.77 \\
\hline Integration (IN) & 7 & 0.67 & 0.68 & 0.73 & 0.77 \\
\hline Rule Clarity (RC) & 7 & 0.70 & 0.71 & 0.71 & 0.80 \\
\hline Material Environment (ME) & 7 & 0.64 & 0.75 & 0.74 & 0.81 \\
\hline
\end{tabular}


Assessment of the chemistry learning environments and teacher student interactions at secondary level

The scale reliability estimates for the different scales of the Actual Form of SLEI using the individual student as the unit of analysis ranged from 0.63 for the Open Endedness and Student Cohesiveness to 0.70 for the Rule Clarity Scale in the Actual form. The scale reliability estimates for the different scales of the preferred form of SLEI using the individual student as a unit of analysis ranged from 0.68 for Integration to 0.75 for the Material Environment scale. The reliability results of the SLEI were consistently above 0.50 . This suggested that the Science Laboratory Environment Inventory (SLEI) can be considered as a reliable tool (De Vellis, 1991) to be used in a Chemistry laboratory learning environments.

Validation of QTI - The Questionnaire on Teacher Interaction (QTI) was administered to 250 students, in 5 schools of Jammu city. Data collected from these schools was analyzed to investigate the reliability and validity of the QTI. To determine the reliability and validity of the QTI, two statistical computations were done. The first being the Cronbach alpha coefficient (Cronbach, 1951), which is a measure of internal consistency. The second involved checking the Circumplex nature of the QTI. Table 4, represents the statistical data for the QTI. The alpha reliability coefficients for the different scales of QTI using the individual as a unit of analysis ranged from 0.51 for the Admonishing Scale to 0.78 for the Leadership Scale for the students' questionnaire. Thus, in all the above scales the reliability results of the QTI were consistently above 0.50 . This suggested that the QTI could be used as a reliable tool (De vellis, 1991) in assessing chemistry laboratory learning environments in Jammu city.

Table 4

Internal Consistency Reliability (Cronbach Alpha Coefficient) for the QTI

\begin{tabular}{lcc}
\hline \multicolumn{1}{c}{ Scale Name } & No. of Items & Alpha Reliability \\
\hline Leadership (DC) & 6 & 0.78 \\
Helping / Friendly (CD) & 6 & 0.75 \\
Understanding (CS) & 6 & 0.66 \\
Student Responsibility/Freedom (SC) & 6 & 0.55 \\
Uncertain (SO) & 6 & 0.52 \\
Dissatisfied (OS) & 6 & 0.62 \\
Admonishing (OD) & 6 & 0.51 \\
Strict (DO) & 6 & 0.54 \\
\hline
\end{tabular}

A further analysis was also carried out to explore the inter scale correlations between the different scales of the QTI. The QTI is based on a circumplex model in which the scales are arranged to form a circular pattern of the eight dimensions of interpersonal behaviour and they are expected to be correlated. According to the Model of Interpersonal Behaviour (Wubbels \& Levy, 1993), it predicts that the correlations between two adjacent scales move further apart until opposite scales are negatively correlated. This pattern is reflected in this study as the results of the inter scale correlations generally reflect the circumplex nature of the QTI and thus further confirms the validity of QTI to be used in Indian laboratory settings.

Based on the values of inter-scale correlations, Figure 1 illustrates the circumplex model, as it correlates to the Helping/Friendly scale. In this model, the Helping/Friendly scale is highly correlated to its neighbouring scales i.e. Understanding which has a correlation of 0.51 , its correlation with the Student Responsibility/Freedom scale is 0.45 . The correlation becomes lower with the next scale i.e. Uncertain which is correlated with a score of 0.28 . The correlation becomes lower with the next scale i.e. Dissatisfied which is negatively correlated with a score of -0.19. As the scales move further apart correlation with Admonishing and Strict scale also lower down with the scores of 0.27 and 0.41 . The maximum negative correlation is with the opposite scale of Dissatisfied. Generally, the findings in this study support the circumplex model of QTI and hence validate it for use in chemistry laboratory classroom settings. 


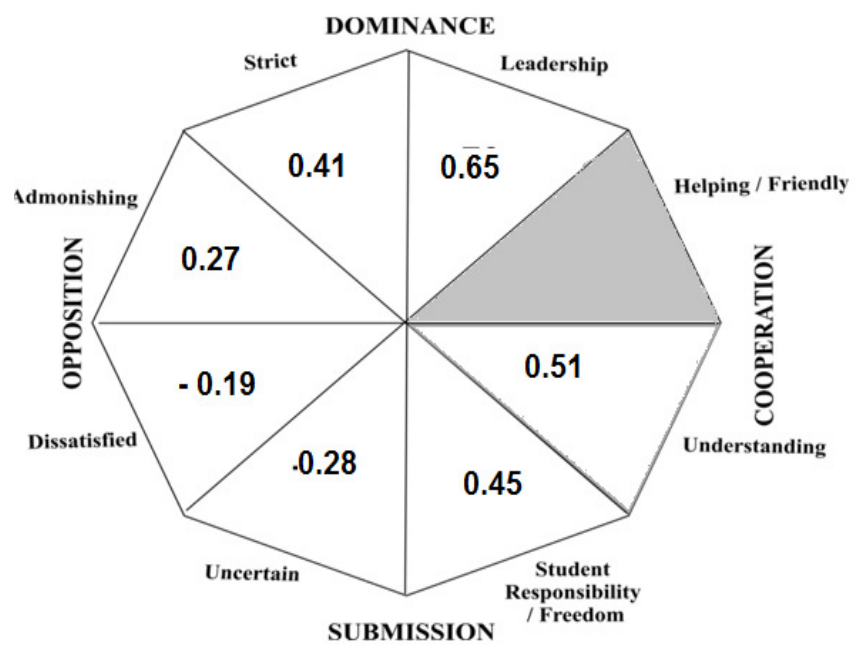

Figure 1. Circumplex model of the QTI

\section{Findings and results}

\subsection{Nature of Chemistry Laboratory Learning Environments}

Item means and standard deviations were computed to determine the nature of chemistry laboratory learning environments using the SLEI. The statistical significance of the difference between means (t-test) was also calculated to study whether the differences in the means of the Actual and Preferred Forms of the SLEI when used in chemistry laboratory classroom settings were significant. The data obtained are presented in Table 5. The mean scores of the different scales of the SLEI ranged from 3.64 for the Rule Clarity and Material Environment Scale to 3.82 for the Integration Scale in the Actual Form which shows that students are helpful and supportive of each other in the chemistry laboratory class. The mean scores of the Actual Form of the SLEI for the Student Cohesiveness scale and Open Endedness scale are 3.72 and 3.77 which means that student often make friends in the chemistry laboratory and also help other students in laboratory work who are having problems with performing practical work. From the mean scores in the Preferred Form of SLEI, the scores range from 3.76 for the Rule Clarity Scale to 3.88 for the Open Endedness Scale which shows that the chemistry laboratory has the rules to guide all student activities. The mean scores of the Preferred Form of the SLEI for the Student Cohesiveness scale, Integration scale and Material Environment scale are 3.83, 3.82 and 3.81 respectively. The values of the standard deviations in both the Actual and Preferred Form of the SLEI are less than 1, which suggests that there are no major deviations in students' perceptions of their chemistry laboratory learning environments.

The results for the t-test on paired samples indicate that there was significant difference $(p<0.01)$ between the actual and preferred means for four out of the five scales (Table 5). The $t$ - values for the Student Cohesiveness, Open Endednes, Rule Clarity, and Material Environment scales are significant at $(p<0.01)$. This shows that students preferred that their chemistry laboratory learning environments should have more open endedness in terms of decision making on part of the students and seek better material support to perform the laboratory experiments in terms of equipment, chemicals etc. Although, all the scales of the SLEI show a good response from the students except Integration scale, the main objective was to improve the existing learning environments in the chemistry laboratory and the information from the students' perceptions of their preferred learning environments gives us vital clues towards the areas that require our immediate focus for further improvement. Figure 2 represents the mean scores on the Actual and Preferred Forms of SLEI in a graphical form. 
Assessment of the chemistry learning environments and teacher student interactions at secondary level

Table 5

Means, SD and Difference between Actual and Preferred Learning Environments as measured by the SLEI

\begin{tabular}{|c|c|c|c|c|c|}
\hline Scale & $\begin{array}{c}\text { Types of } \\
\text { Scale }\end{array}$ & Mean & $\begin{array}{c}\text { Mean } \\
\text { Difference } \\
(\mathrm{A}-\mathrm{P})\end{array}$ & $\begin{array}{l}\text { Standard } \\
\text { Deviation }\end{array}$ & $t$ \\
\hline Student Cohesiveness & $\begin{array}{l}\text { Actual } \\
\text { Preferred }\end{array}$ & $\begin{array}{l}3.72 \\
3.83\end{array}$ & -0.11 & $\begin{array}{l}0.59 \\
0.62\end{array}$ & $3.49 * *$ \\
\hline Open Endedness & $\begin{array}{l}\text { Actual } \\
\text { Preferred }\end{array}$ & $\begin{array}{l}3.77 \\
3.88\end{array}$ & -0.10 & $\begin{array}{l}0.56 \\
0.64\end{array}$ & $3.16^{* *}$ \\
\hline Integration & $\begin{array}{l}\text { Actual } \\
\text { Preferred }\end{array}$ & $\begin{array}{l}3.82 \\
3.82\end{array}$ & 0.00 & $\begin{array}{l}0.58 \\
0.60\end{array}$ & 0.14 \\
\hline Rule Clarity & $\begin{array}{l}\text { Actual } \\
\text { Preferred }\end{array}$ & $\begin{array}{l}3.64 \\
3.76\end{array}$ & -0.12 & $\begin{array}{l}0.64 \\
0.63\end{array}$ & $2.95^{* *}$ \\
\hline Material Environment & $\begin{array}{l}\text { Actual } \\
\text { Preferred }\end{array}$ & $\begin{array}{l}3.64 \\
3.81\end{array}$ & -0.17 & $\begin{array}{l}0.59 \\
0.65\end{array}$ & $4.49 * *$ \\
\hline
\end{tabular}

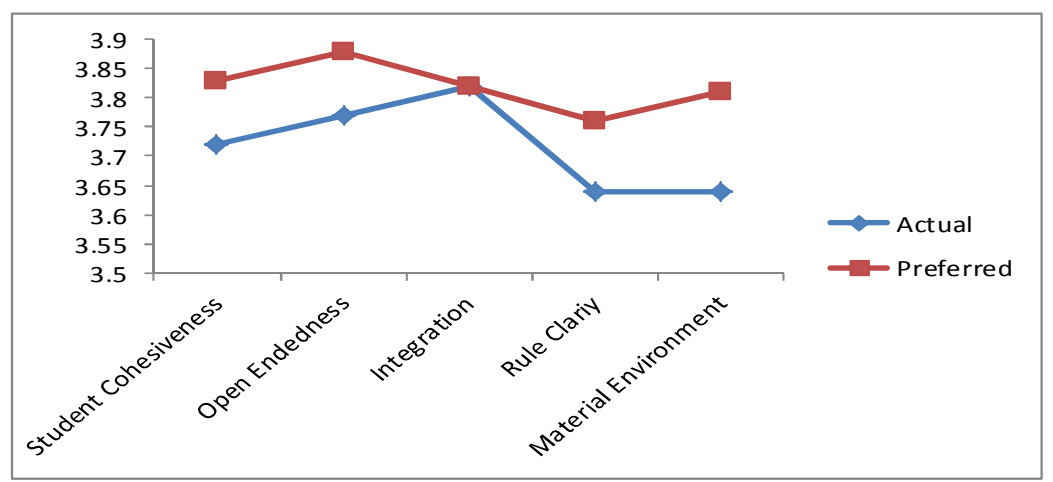

Figure 2. Mean Scores of the Actual and Preferred Forms of the SLEI

\subsection{Assessing Teacher-Student Interactions}

To assess the extent of teacher-student interactions mean and standard deviation was computed for the various scales of the Questionnaire on Teacher Interaction (QTI). The values of means and standard deviations are given in Table 6. The mean scores of the different scales of QTI ranged from 2.81 for the Dissatisfied Scale to 3.16 for Strict. The value of Standard Deviation ranges from 0.63 for Student Responsibility/Freedom Scale to 0.92 for the Leadership Scale. The values of Standard Deviation are less than 1.00; it suggests that there was no major diversity in students' perceptions.

The overall analysis of the results in Table 6 shows that the students see their teachers as good leaders most of the time and have also rated their teachers in terms of exhibiting helpful and friendly nature, understanding and giving students freedom and responsibility in the chemistry laboratory. In fact, the positive factors have been exhibited by the teachers quite often in the chemistry laboratory. One interesting feature of the analysis was that students perceive their teachers to be strict which is acceptable in India as a teacher oversees the laboratory work and gives direction to the students for conducting various laboratory activities in a methodical manner and ensuring proper safety of students. Also, the negative aspects of the teacher-student interaction have been rated quite low by the students as teachers seldom exhibit admonishing behavior, are less dissatisfied and less uncertain. This shows that the chemistry laboratory environment may help in creating a healthy teacher-student interpersonal relationship and promote positive behavior. 
Gupta, A., \& Sharma, A.

Table 6

Means and Standard Deviations for the Questionnaire on Teacher Interaction (QTI)

\begin{tabular}{lccc}
\hline \multicolumn{1}{c}{ Scale Name } & No. of Items & Mean & SD \\
\hline Leadership (DC) & 6 & 3.12 & 0.92 \\
Helping / Friendly (CD) & 6 & 3.00 & 0.86 \\
Understanding (CS) & 6 & 3.23 & 0.74 \\
Student Responsibility/Freedom (SC) & 6 & 3.14 & 0.63 \\
Uncertain (SO) & 6 & 2.88 & 0.65 \\
Dissatisfied (OS) & 6 & 2.81 & 0.72 \\
Admonishing (OD) & 6 & 2.93 & 0.72 \\
Strict (DO) & 6 & 3.16 & 0.71 \\
\hline
\end{tabular}

Note. $\mathrm{N}=250$

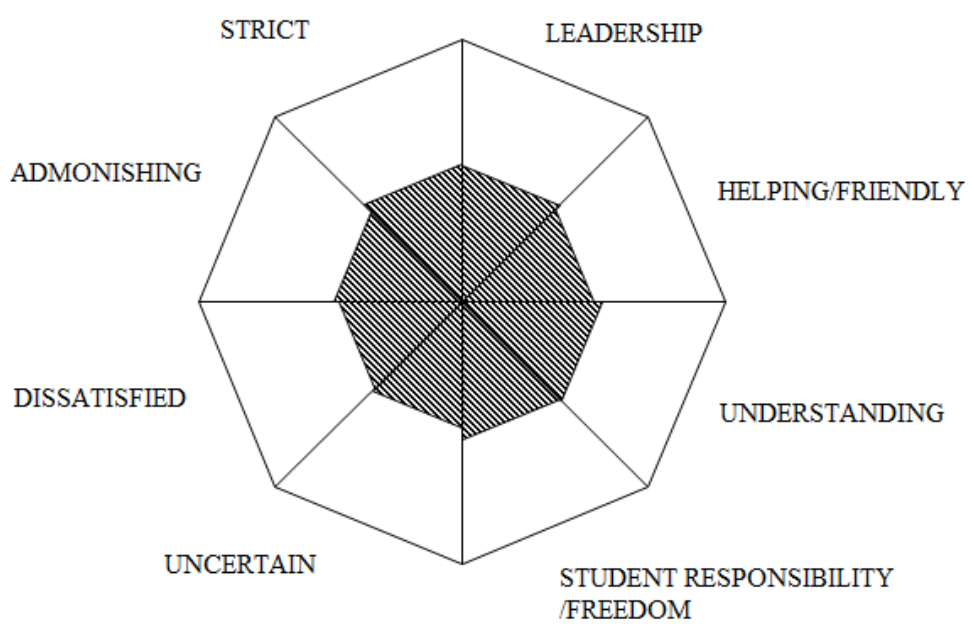

Figure 3. Sector profile diagram of students' perceptions of their teacher's interpersonal behavior

Figure 3 represents a sector profile depicting students' perceptions of the teacher interpersonal behavior in the chemistry laboratory settings which was developed by plotting the mean scores of the eight scales of the QTI (student questionnaire) in an excel Worksheet.

The sector profile reveals diagrammatically the degree to which students perceive each behavioural aspect exhibited by the teacher based on their mean scores as measured through the QTI in eight quadrants representing the eight scales of QTI i.e. the Leadership Scale, Helping/Friendly Scale, Student Responsibility/Freedom Scale, Uncertain Scale, Dissatisfied Scale, Admonishing Scale and Strict Scale. The sector profile in Figure 2 shows the extent of the positive behavioural aspects exhibited by the teacher in a chemistry laboratory based on the mean scores. These are represented on the right side of the sector profile. The negative aspects of teachers' behaviour in a chemistry laboratory based on their mean scores as given in Table 4 are represented on the left side of the sector profile.

From Table 4 we can see that the standard deviation ranges from 0.63 for the Student Responsibility/Freedom scale to 0.92 for the Leadership scale. Since the values of the standard deviation are less than 1.00, it suggests that there is no major diversity in students' perceptions.

\subsection{Investigation of Gender Differences}

Gender Differences on the Science Laboratory Environment Inventory (SLEI) - Gender differences in the chemistry laboratory learning environments were investigated by computing the means and standard deviations for the two groups followed by a test of significance of difference between means ( $t$-test for independent samples). In the sample there are 151 male and 99 female students. The data obtained statistically has been illustrated in 
Assessment of the chemistry learning environments and teacher student interactions at secondary level

Table 7, which shows that t-values ranged from 0.00 for the Integration scale to 0.96 for the Rule Clarity scale. From the information given in the Table 7, it can be seen that there are no significant differences in the perceptions of the boys and girls about the learning environments in the chemistry Laboratories. Hence, it was clear from the results that both boys and girls perceived their chemistry laboratory learning environments in a similar manner. They are equally interested, motivated and encouraged in their chemistry laboratory environment.

Table 7

Gender Differences in Students' Perceptions as measured by the SLEI

\begin{tabular}{llcccc}
\hline \multicolumn{1}{c}{ Scale } & Gender & Mean & $\begin{array}{c}\text { Mean } \\
\text { Difference } \\
(\mathrm{M}-\mathrm{F})\end{array}$ & $\begin{array}{c}\text { Standard } \\
\text { Deviation }\end{array}$ & $t$ \\
\hline Student Cohesiveness & Male & 3.71 & -0.03 & 0.63 & 0.46 \\
& Female & 3.74 & & 0.53 & \\
Open Endedness & Male & 3.76 & -0.03 & 0.57 & 0.46 \\
& Female & 3.79 & & 0.54 & \\
Integration & Male & 3.82 & 0.00 & 0.61 & 0.00 \\
& Female & 3.82 & & 0.54 & \\
Rule Clarity & Male & 3.61 & -0.08 & 0.65 & 0.96 \\
\multirow{2}{*}{ Material Environment } & Female & 3.69 & & 0.61 & \\
& Male & 3.63 & -0.04 & 0.62 & 0.65 \\
\hline Note. $\mathrm{N}=250$. Males: $\mathrm{n}=151 ;$ Females: $\mathrm{n}=99$. & 3.67 & & 0.55 & & \\
& Female & & & &
\end{tabular}

Note. $\mathrm{N}=250$. Males: $\mathrm{n}=151$; Females: $\mathrm{n}=99$.

Gender Differences in Teacher-Student Interactions - To find out whether gender differences exist in students' perceptions of their teacher interpersonal behaviour in a chemistry laboratory learning environment a test of significance of difference between mean ( $t$-test) was used. Results are given in Table 8 .

Table 8

Gender Differences in Students' Perceptions of Teacher-Student Interactions as measured by the QTI

\begin{tabular}{llcccc}
\hline \multicolumn{1}{c}{ Scale } & Gender & Mean & $\begin{array}{c}\text { Mean } \\
\text { Difference } \\
\text { (M-F) }\end{array}$ & $\begin{array}{c}\text { Standard } \\
\text { Deviation }\end{array}$ & $t$ \\
\hline Leadership & Males & 3.00 & -0.30 & 0.87 & $2.49 *$ \\
Helping/Friendly & Females & 3.30 & & 0.98 & 0.16 \\
& Males & 2.99 & -0.02 & 0.85 & \multirow{2}{*}{1.12} \\
Understanding & Females & 3.01 & & 0.87 & 0.62 \\
Student Responsibility & Males & 3.19 & -0.11 & 0.71 & \multirow{2}{*}{$2.27 *$} \\
/Freedom & Females & 3.30 & & 0.79 & 1.68 \\
Uncertain & Males & 3.16 & 0.05 & 0.67 & 0.58 \\
Dissatisfied & Females & 3.11 & & 0.61 & 0.69 \\
Admonishing & Males & 2.95 & 0.19 & 0.76 & 0.64 \\
Strict & Females & 2.76 & & 0.74 & 0.41 \\
& Males & 2.87 & 0.15 & 0.69 & \\
\hline
\end{tabular}

Note. *Significant at $p<0.05$

$\mathrm{N}=250$, male $=151$, female $=99$.

Data analysis reveals that out of eight scales of the QTI only two scales i.e. Leadership Scale $(2.49 *)$ and Uncertain Scale $\left(2.27^{*}\right)$ are statistically significant $(p<0.05)$. For the Leadership Scale the mean score of the females was higher (3.30) than the males (3.00). This suggests that female students perceived their chemistry teacher to have better leadership qualities for conducting laboratory activities and that they can guide the students in a better way as compared to their male counterparts. For the Uncertain Scale the mean scores of the male 
Gupta, A., \& Sharma, A.

students was higher (2.95) than the females (2.76) which, suggests that male students see their teacher as hesitant and uncertain in their behaviour and they do not know what to do in the chemistry laboratory as compared to female students who see their teachers as less uncertain.

\subsection{Limitations}

The sample for the study was restricted to 250 students from only five school of Jammu city as a limited time frame was available for collecting data. Adding more schools could have contributed to richness of the data. As specific objectives were set for the study hence, the study was mainly quantitative in nature. Further, this study was limited to only the higher secondary students (Classes 11 and 12) and taking students from the secondary level (Classes 9 and 10) could have provided a wider perspective on the nature of Chemistry laboratory learning environments and their teacher-student interactions. Lastly, the focus was to only study the learning environments and teacher-student interactions in Chemistry laboratories where as such an analysis could have also been carried out in a Physics or a Biology Laboratory.

\section{Conclusions and implications}

The present study contributed towards further establishing the reliability and validity of the Science Laboratory Environment Inventory (SLEI) and Questionnaire on Teacher Interaction (QTI) which were used to assess students' perceptions in the chemistry laboratory settings and their teacher interpersonal behaviour in the senior secondary schools of Jammu. Further investigation suggested that positive associations existed between students' perceptions of their laboratory learning environments and students perceived their learning environments as encouraging, cohesive and which provide integration between theory and practice. Results of the study also reveal the students see the positive aspect of their teachers' interpersonal behaviour and don't see their teachers as uncertain, admonishing and dissatisfied. Gender differences between male and female students were also investigated and it was reported that there are no significant differences between the perceptions of boys and girls in their chemistry laboratory learning environment at the senior secondary level. Gender differences between male and female students were observed on two scales of the QTI which shows that significant gender differences exist between the teacher-student interactions in the chemistry laboratory learning environments. The main implications of this study are that the teachers will get vital clues by understanding the students' perceptions as to how to create the right kind of environment that fosters learning and help nurture a scientific bent of mind by inculcating the right values and skills required for chemistry laboratory work. This research study also provides information to the chemistry teachers and practitioners of science education especially in schools of Jammu that students need to be given a certain amount of freedom in their chemistry laboratory work so that they can test their own ideas, apply divergent thinking, design their own experiments and go beyond the limits of the curriculum.

\section{References}

Afari, E., Aldridge, J. M., Fraser, B. J., \& Khine, M. (2013). Students' perceptions of the learning environment and attitudes in game-based mathematics classrooms. Learning Environments Research, 16(1), 131-150. https://doi.org/10.1007/s10984-012-9122-6

Aldridge, J. M., \& Fraser, B. J. (2011). Effects and determinants of outcomes-focused learning environments. Curriculum and Teaching, 26(1), 5-31. https://doi.org/10.7459/ct/26.1.02

Bybee, R. (2000). Teaching science as inquiry. In J. Minstrel \& E. H. Van Zee (Eds.), Inquiring into inquiry learning and teaching in science (pp. 20-46). Washington, DC: American Association for the Advancement of Science (AAAS).

De Vellis, R. F. (1991). Scale development: Theory and application. Newbury Park: Sage Publications.

Den Brok, P., Brekelmans, M., Levy, J., \& Wubbels, T. (2002). Diagnosing and improving the quality of teachers' interpersonal behavior. The International Journal of Educational Management, 4, 176-184. https://doi.org/10.1108/09513540210432155 
Assessment of the chemistry learning environments and teacher student interactions at secondary level

Fraser, B. J. (1994). Research on classroom and school climate. Handbook of research on science teaching and learning (pp. 493-541). New York: Macmillan.

Fraser, B. J. (1998). The birth of a new journal. Learning Environments Research, 1, 1-5. https://doi.org/10.1023/A:1009994030661

Fraser, B. J. (2002). Learning environments research: yesterday, today and tomorrow. In S. C Goh and M.S. Khine (Eds.), Studies in educational learning environments: An international perspective (pp. 1-25). Singapore: World Scientific Publishing. https://doi.org/10.1142/9789812777133_0001

Fraser, B. J. (2012). Classroom learning environments: Retrospect, context and prospect. In B. J. Fraser, K. G. Tobin \& C. J. McRobbie (Eds.), Second international handbook of science education (pp. 1191-1239). New York: Springer. https://doi.org/10.1007/978-1-4020-9041-7_79

Fraser, B. J., Giddings, G. J., \& McRobbie, C. J. (1995). Evolution and validation of a personal form of an instrument for assessing science laboratory classroom environments. Journal of Educational Research in Science Teaching, 32, 399-422. https://doi.org/10.1002/tea.3660320408

Gupta, A., \& Fisher, D. (2011). Teacher-Student interactions in a technology supported science classroom environment in relation to selected learner outcomes: An Indian study. MIER Journal of Educational Studies, Trends and Practices, 1(1), 41-59.

Gupta, A., Koul, R. B., \& Sharma, M. (2015). Assessing the science laboratory learning environment at the senior secondary level in an Indian school. Educational Quest: An International Journal of Education and Applied Social Sciences, 6(1), 1-9. https://doi.org/10.5958/2230-7311.2015.00001.x

Hofstein, A., \& Lunetta, V. N. (2004). The laboratory in science education: foundation for the $21^{\text {st }}$ century. Science Education, 88, 28-54. https://doi.org/10.1002/sce.10106

Hofstein, A., \& Walberg, H. J. (1995). Instructional strategies. In B. J. Fraser \& H. J. Walberg (Eds.), Improving science education (pp. 1-20). Chicago: National Society for the Study of Education.

Krajcik, J., Mamlok, R., \& Hug, B. (2000). Learning science through inquiry. In L. Corno (Ed.), Education across a century: The central volume (One Hundredth Yearbook of the National Society for the Study of Education, NSSE) (pp. 205-238). Chicago: National Society for the Study of Education.

Lunetta, V. N., Hofstein A., \& Clough M. (2007). Learning and teaching in the school science laboratory: An analysis of research, theory, and practice, In N, Lederman \& S. Abel (Eds.), Handbook of research on science education (pp. 393-441). Mahwah, NJ: Lawrence Erlbaum.

Lunetta, V. N. (1998). The school science laboratory: historical perspectives and centers for contemporary teaching. In P. Fensham (Ed.). Developments and dilemmas in science education (pp. 169-188), London: Falmer Press. https://doi.org/10.1007/978-94-011-4940-2_16

Martin-Dunlop, C., \& Fraser, B. J. (2012). Using a learning environment perspective in evaluating an innovative science course for prospective elementary teachers. In B. Fraser, K. Tobin, \& C. McRobbie (eds.), Second international handbook of science education (pp. 1305-1318). Dordrecht, The Netherlands: Springer. https://doi.org/10.1007/978-1-4020-9041-7_84

Quek, C. L., Fraser. B., \& Wong, A. F. L. (2001). Determinants and effects of perceptions of Chemistry classroom learning environments in secondary schools gifted education classes in Singapore. Paper presented at the annual meeting of the American Education Research Association, San Diego, CA.

Rahmawati, Y. (2008). SLEI and science teaching laboratory. Retrieved from http://pendidikansains.wordpress.com/2008/04/12/slei-and-science-teaching-laboratory/

Riah, H., \& Fraser, B. J. (1998, April). The learning Environments of High School Chemistry Classes. Paper presented at the annual meeting of the National Association for Research in Science Teaching.

Robinson, E., \& Fraser, B. J. (2013). Kindergarten students' and parents' Perceptions of science classroom environments achievement and attitudes. Journal of Learning Environment Research, 16(2), 151-167. https://doi.org/10.1007/s10984-013-9138-6

Sharma, S. (2014). A comparative study of teacher educators' interpersonal behavior in classroom settings in selected colleges of education in Jammu city. International Journal of Physical and Social sciences, 4(8), 38-54.

Shepardson, D. P. (1997). The nature of student thinking in life science laboratories. Journal of School Science and 
Gupta, A., \& Sharma, A.

Mathematics, 97(1), 37-45. https://doi.org/10.1111/j.1949-8594.1997.tb17338.x

Swain, J., Monk, M., \& Johnson, S. (2000). Development in science teachers' attitudes to Aims for Practical

Work: continuity and change. Teacher Development, 4(2), 281-292.

https://doi.org/10.1080/13664530000200114

Venville, G., \& Dawson, V. (Eds.). (2004). The art of teaching science. Sydney, Australia: Allen and Unwin.

Wong, A. F. L., \& Fraser, B. J. (1994, April). Science laboratory classroom environments and student attitudes in chemistry classes in Singapore. Paper presented at the annual meeting of American Educational Research Association, New Orleans, LA.

Wong, A. F. L., \& Fraser, B. J. (1996). Environment-attitude associations in the chemistry laboratory classroom. Research in Science and Technological Education, 14, 91-102. https://doi.org/10.1080/0263514960140107

Wubbels, T., \& Levy, J. E. (1993). Do you know what you look like? Interpersonal relationships in education (1st. ed.). London, England: The Falmer Press.

Zedan, R. (2010). New dimensions in the classroom climate. Learning Environment Research: An International Journal, 13(1), 75-83. https://doi.org/10.1007/s10984-009-9068-5 